\title{
Twenty-Five Years of Academic Library Building Planning David Kaser
}

The modular design concept, initroduced into American library building planning following World War II, was fully accepted by 1960. In the early years the usual modular design was simple and uncluttered, lending itself well to efficient library operation. Some felt that the appearance of the early modular buildings was too plain. As a result, the last quarter century has seen increased use of atria, designer lighting, monumental effects, unusual shapes, and other devices to relieve the perceived monotony of the unadorned early module. Many of these embellishments work to the detriment of sound library service. Colleges and universities should take greater care to assure that architects understand the imperative nature of their library buildings' functional requirements, even if the resulting structures are less imposing in appearance.

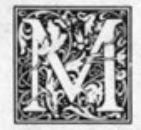

ore academic library buildings have been constructed in the United States in the last quarter century than in any other period in history. One might expect that the quality of libraries built at the end of the period would be unquestionably better than of those built at the beginning, but many librarians question the fulfillment of this expectation. This paper will review library planning developments, identify salient strengths and weaknesses, and comment upon problems and prospects in this important aspect of academic library work.

\section{THE CLASSIC MODULE}

By 1960 the simple modular design concept had totally superseded the fixed- function character that had dominated American academic library building planning during the first half of the twentieth century. ${ }^{*}$ The compelling virtues of the new style were (1) it was readily adaptable to post-World War II library service concepts requiring that readers have direct physical access to books on open shelves, (2) it lent itself readily to the profession's contemporary concern for improving the "time and motion" efficiency of libraries, and (3) it was remarkably flexible.

Readers were no longer restricted to massive reading rooms with floor structures unable to support the weight of the books they wished to consult. Librarians could now fulfill their social contracts in modest structures rather than in palatial halls. Library interiors could now, as they could not previously, be rearranged easily

*In a modular building the floor area is divided into equal rectangles, all of which are usually defined by structural columns at the corners, as well as by uniformity in ceiling heights, air and lighting treatment, and floor-loading capacities, thus allowing their use to be modified as needs change. A fixedfunction building, on the other hand, lacks one or more of these features, thus tying the use of floor areas largely to the purposes for which they were originally designed. Before World War II, for example, almost all library buildings were engineered to carry the weight of the book collections only in multitiered structural stacks, thereby dictating a permanent separation of reader areas from stack areas.

David Kaser is professor, School of Library and Information Science, Indiana University, Bloomington, Indiana 47405. Dr. Kaser has been involved in planning more than eighty academic library buildings in North America, Asia, Africa, and the Middle East. 
and cheaply. It is small wonder that modular academic library buildings were so quickly adopted by the librarians who were to work in them.

Proposed initially by architect and stack manufacturer Angus Snead Macdonald in the mid-1930s, the full application of the modular concept of library building planning was delayed for more than a decade, in part by the usual forces of conservatism, but also by the depression and by World War II. ${ }^{1}$ With the encouragement, however, of its first principal proponent, Ralph Ellsworth, director of libraries of the University of Iowa, modular planning was used increasingly in the years immediately after the war, first at HardinSimmons College (1947) and then at Princeton (1948), North Dakota State (1950), and Iowa (1951) universities. ${ }^{2}$ The 1950s saw further consolidation of its strengths and further resolution of most of its principal weaknesses, so that by 1960 the modular academic library building was as close to perfection as it was fated to come.

Because of its unadorned severity and stark simplicity, its uncompromising adherence to architect Louis Sullivan's doctrine that "form must follow function," and the almost brutal economy of its structural style, classicists found the very tenets of their professional and esthetic creeds embodied within the design of early modular buildings. Among buildings built in this early tradition were the libraries of Louisiana State (1958), Colgate (1958), Brigham Young (1958), and St. Louis (1959) universities.

However, some felt that this early modular library building lacked visual interest. Its reliance on uniformly rectangular components was boring and cried out for relief. It was ugly, they said, and looked "like a box," although a box was indeed exactly what library functional requirements warranted, with rectangularity dictated by the real library module-the book itself-of which the building must accommodate hundreds of thousands or even millions. Nevertheless, it soon became clear that the "box" was going to have to be dressed up so that it looked less like a box.

It is difficult to determine today where this movement to disguise the box originated, although it does not seem to have been among librarians. Librarians were very aware of how well off they were with the box and preferred to remain with it. It is easy to hypothesize that donors were among the first to want more than a box. They, after all, were in some cases to have their names memorialized by these buildings and might be indisposed to favor just a box. Or it may have been university

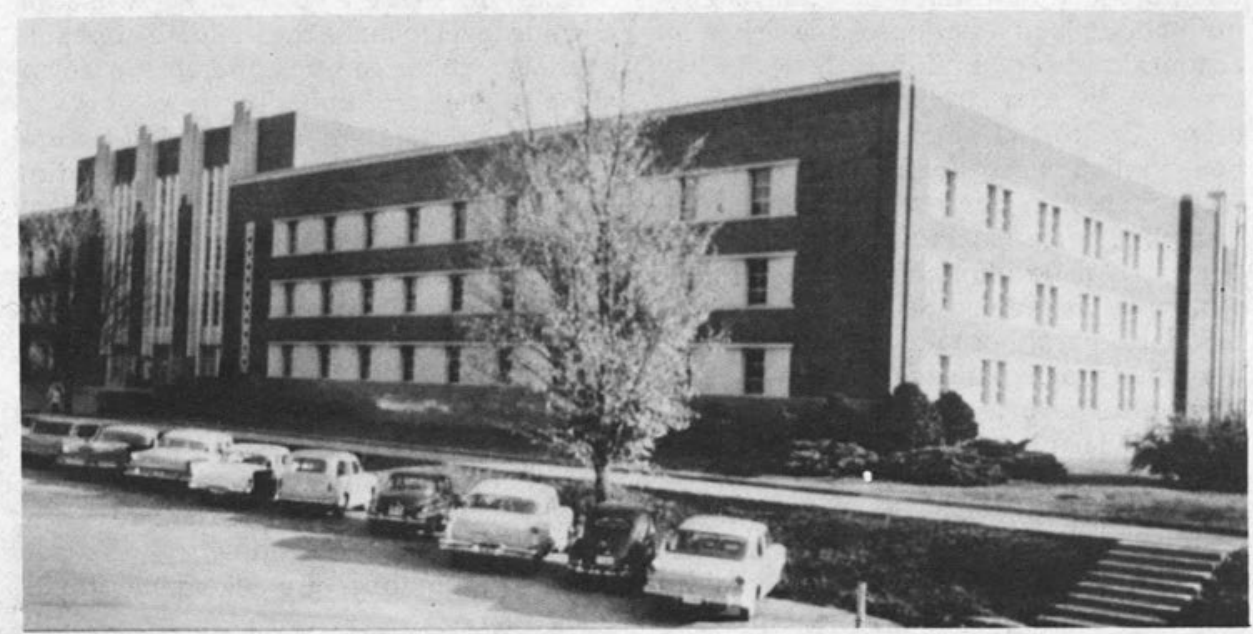

University of Iowa: unadorned modular simplicity. 
presidents and trustees who wanted something more elaborate in their library buildings than boxes. Some administrators began calling for their new library buildings to serve not only as libraries but also as symbols, statements, signatures, or embodiments of institutional style, actual or imagined.

\section{DECADENCE AND THE ROMANTIC MODULE}

As soon as these dual expectations began to arise, the overall quality of academic library building design in the United States began slowly to decline. Library buildings were no longer allowed to serve one simple, straightforward function that would determine their form. Now library buildings were expected to serve two functions, one bibliothecal and the other symbolic. Just as a slave cannot serve two masters, form cannot serve two functions.

Most architects appear to have been just as proud of the boxes they designed in the $1950 \mathrm{~s}$ as their first owners were to have them. It must be acknowledged, however, that architects generally were quick to follow the wishes of their clients when in the early 1960 s they began to abandon the box in favor of more esoteric forms. Thereafter, many architects were found in the vanguard of the movement away from simplicity.

An art historian might say that beginning about 1960 a period of classicism in academic library building design gave way rapidly to a strong romantic movement. Contorted shapes, unusual textures, artistic license, emphasis upon effect, revulsion against constraint and discipline, return to tradition (or what was perceived as traditional) and to nature (or what was perceived as natural)-all the standard paraphernalia of romanticism pervaded much of the work that was done during the next two decades. As a result, the modular planning so consistent with classic theories of design, and so much appreciated by librarians, became unfashionable. These romantic elements were also partially responsible for the rapid increase in building costs during this period. Boxes are simply cheaper to build than more complex containers.

It is ironic that this period of romanticism set in at almost the very moment that the classical modular form was attaining its zenith, so much so that both styles can be seen in a single watershed building. The library at Washington University in St. Louis, planned in the late 1950s and opened in 1962, has been described by many informed observers as the modular building brought to its highest level of success. It is a square structure with entry in the middle of the third of five stories, providing the most efficient access to all locations within, square bays sized to library modular equipment, low ceilings, uniform air and light treatment throughout, and distribution of activities based solely upon the functions themselves. These qualities led Ellsworth to call it simply "the best. ${ }^{\prime 3}$ Few have departed markedly from that assessment.

Yet the beginning of decline is also evident in Washington University's fine modular library. Two features were incorporated into the design primarily to keep it from looking too much like a box; both cost extra money to construct, and one of them impaired function (although only slightly). One of these features was a wide deck that circumscribed the building at the second level above grade. The other was a tree court notched into one corner of the building. The deck was claimed to be necessary to shade a collar of glass used at grade level to make the building appear to "float" on the campus, thereby diminishing its apparent bulk. The tree court was rationalized as a device to bring riatural light to the main stair, reserve reading area, and rare book suite. But a deck twenty-seven feet wide completely surrounding the building was certainly not needed just for shading, and since the interior of the building was amply and ambiently lit artificially, natural light was not needed. The court used up space needed for library activities, especially at grade level, thereby obtruding upon function. Both were extremely pleasant features, however, and they did relieve the perceived monotony of a box-shaped building.

Not all academic library architecture 


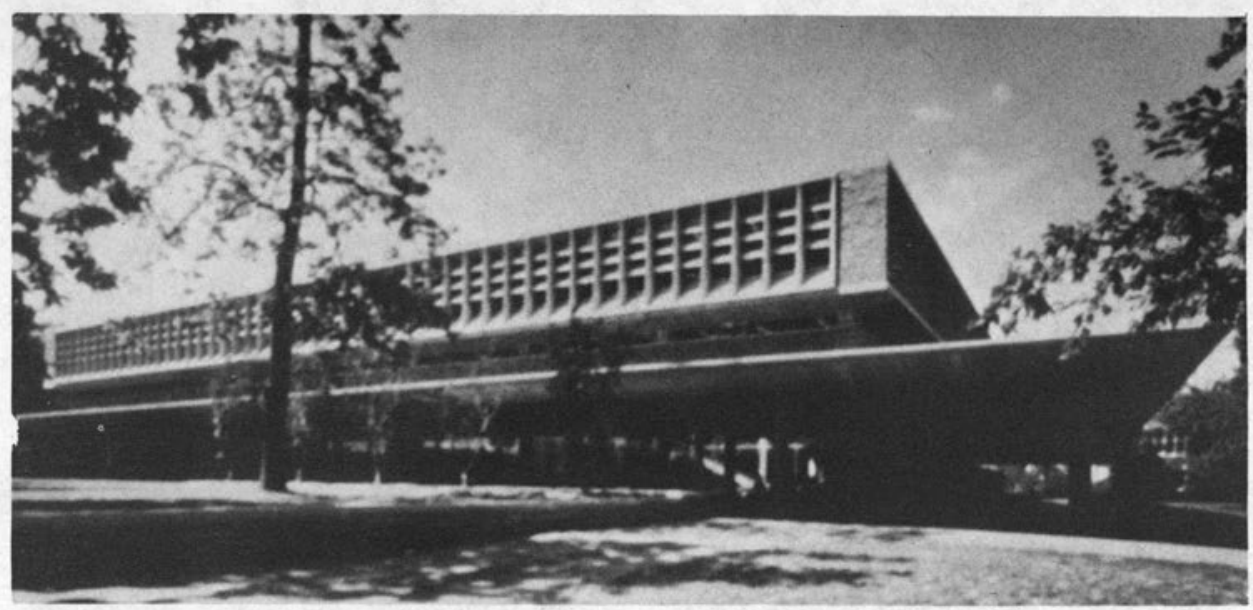

Washington University: Ellsworth calls it "the best."

broke so immediately during the early 1960 s for the more euphoric and emotional style of the romantic movement. Some buildings designed during this period even won AIA/ALA awards for their classical commitment to functionalism. Among such award winners were the undergraduate library at the University of South Carolina, completed in 1960, and the libraries of Lafayette College (1963), the University of Miami (1964), and LeMoyne College in Memphis (1964). Although each of these buildings had some functional problems (as virtually any library will), none resulted from a lack of modularity. All of these buildings were square or rectangular, and all evinced restraint in design. As the years passed, however, these qualities became increasingly rare in newly designed academic library buildings.

\section{PROBLEM AREAS}

What were some of the problems that increasingly insinuated themselves into American library design during the subsequent years? Few were new problems; most instead were old problems that had grown out of hand. Most were already obvious to Keyes Metcalf in the early 1960s when he wrote his comprehensive volume, Planning Academic and Research Library Buildings. Among those which he enumerated were (1) irregular shapes, (2) interior or exterior courts, (3) monumentality, and (4) too much or too little glass. ${ }^{4}$ These four potential flaws will be discussed here with a view to their prominence in buildings that have been constructed during the last two decades.

\section{Irregular Shapes}

Other things being equal, simple squares or rectangles that can be entered near the center of the long side, especially at the building's middle level, lend themselves best to economical library use and operation. They create minimal exterior wall area requiring expensive cosmetic treatment. Of course, other things are seldom if ever equal, and legitimate factors, usually relating to irreconcilable site considerations, frequently impinge upon a building's design. In too many cases, however, this economy of construction and operation has been forgone for no apparent reason except to attain desired esthetic effect or, more frequently, to keep the box from looking like a box.

Some of these irregularly shaped buildings have been round, although that certainly was not a new shape for libraries. Semicircular libraries were built as early as Roman times, and the first completely circular library was the Radcliffe Camera built at Oxford University in 1749. Many others have been built since then. Since books and off-the-shelf library furniture 
are rectangular, round buildings (or indeed buildings of any other nonrectangular form) are profligate in their use of floor space. Radial stack layouts, for example, require a certain minimum distance (perhaps thirty inches) between ranges at the hub end simply to allow persons to pass through. The farther the stack ranges radiate from the center, however, the wider the distance between ranges becomes, creating large areas of unusable floor area which reduce the efficiency and drive up the cost of the building. Building contractors, moreover, can construct buildings with ninety-degree angles cheaper than they can contend with curvilinear or other nonright-angular structures.

Although round libraries have never been found to be efficient, they continue to be built with unabashed frequency. The University of Corpus Christi built one in 1963, as did Chabot College in 1966, St. Peter's College in 1967, and St. Michael's College in 1968. One architect experimented unsuccessfully with radial stacks at Wells College in 1968 but then proceeded to design three round stack towers with the same deficiencies for Northwestern University a year later. Other institutions built libraries that were only partially curved, such as Nevada Southern University and Worcester Polytechnic Institute, both in 1967. It is ironic that at the same time that some architects were trying to disguise rectangular boxes, others were trying to disguise these "hat boxes" by modifying their roundness. Thus Marywood College opened a gear-shaped library in 1967, and Worcester State College built a ratchet-shaped building in 1970 .

Some other institutions, while eschewing rectangles, at least opted for rectilinear forms. Oral Roberts University built a hexagon in 1966, and Drexel University (1959) and Marymount (1967) built octagons. Widener College (1969), the University of Toronto (1973), and Sangamon State University (1976) settled for triangles, and the University of Texas built a parallelogram in 1978. Western Illinois University opened a library shaped like a pinwheel in 1978, with each level turned forty-five degrees from the floors above and below. The shape of the University of Chicago Library building (1970), while retaining a semblance of rectangularity, nonetheless defied simple description, and the library at the University of California at San Diego (1970) took the shape of a mushroom cloud. Still others failed to assume any discernible shape, such as the Wells College Library, which, in Ellsworth's words, "oozes down the hillside" toward Cayuga Lake. ${ }^{5}$

\section{Interior and Exterior Courts}

There was a time, before modern lighting and air treatment became available, when interior and exterior courts were necessary in order to make central spaces in large buildings usable. Atria and light

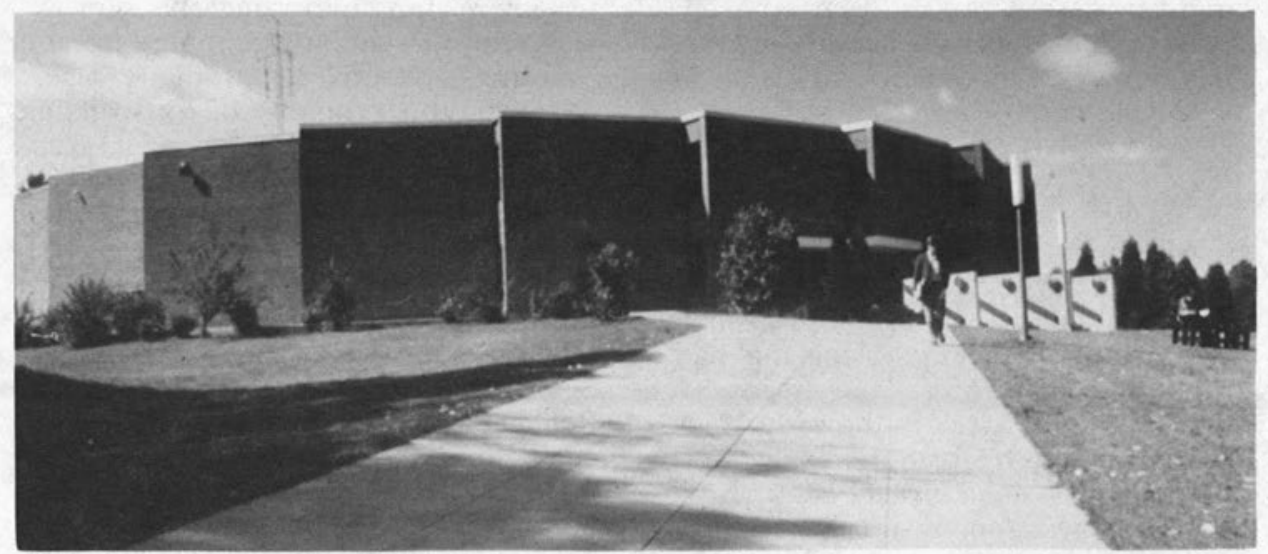

Worcester State College: ratchet-shaped. 
wells are thus among the oldest architectural refinements known to the human race, and they have been used effectively in libraries since before the Christian era. High vaulted ceilings and clerestory lighting were essential standard features of the eighteenth- and nineteenth-century alcoved book halls used as libraries following their introduction by Sir Christopher Wren at Trinity College, Cambridge, in the 1690 s.

By the end of World War II, however, good ambient artificial light and efficient ventilating and air-cooling systems were available at low cost, so that open wells, courts, and high ceilings were seldom if ever thereafter needed for any functional purpose. With the need for them gone, their great inefficiency soon became apparent. It was immediately recognized that four kinds of problems, none susceptible to easy resolution, resulted from the use of wells. The first was that they increased construction cost by swelling the bulk of the building, thus increasing the amount of exterior skin that needed to be finished off. The second was that they increased maintenance costs by creating large blocks of unusable interior cubage that had to be heated in winter and cooled in summer. Third, they usually blocked more direct and efficient circulation, or they were in locations that could have served better for assignable library purposes. And fourth (and doubtless most annoying to patrons), they permitted the transmission of noise vertically from floor to floor, impairing the libraries' essential acoustical ambience. Also, floor areas below atria and in high-ceilinged rooms were difficult to light, and they reduced flexibility in the future use of a building. Obviously, exterior courts experienced only some of these problems, but they were nonetheless deserving of concern.

For these reasons few atria were used in the early (i.e., pre-1960) modular buildings, although occasional mezzanines and other high ceilings made appearances, largely as vestiges of the fixed-function libraries that had preceded them. Law school libraries, especially, continued to favor mezzanines, but some turned up also in general academic libraries. The Lamont Library at Harvard (1949), the library at Georgia Institute of Technology (1955), the St. Louis University Library (1959), and the Colorado College Library (1962) can be counted among the early modular buildings that utilized mezzanines. High ceilings tended in this early period to be limited in use to entryways, as at Southern Illinois University (1955) and Clemson University (1966).

Despite their functional deficiencies, however, atria and wells, open and interior, have become used widely during the last two decades. In fact, for a time following the opening in 1967 of Atlanta's Regency Hyatt Hotel, resplendent with a cavernous atrium, libraries like bagels seemingly all came with holes in the middle, the assumption apparently being that if an atrium is good for the hotel business it must be good for the library business as well. Not only did wells increase in popularity, but they also increased in size. Butler University's library atrium (1963) was relatively modest in scale, as was the one at Providence College (1968), while those at the Countway Medical Library (1966), the undergraduate library at Stanford University (1967), and the undergraduate library at the University of Washington (1972) yawned ever larger and higher.

The trend to bigger interior wells had to end somewhere, and it appears to have done so with the opening in 1970 of New York University's library that boasted a gaping 10,000-square-foot maw that loomed upward fully twelve stories from its entrance on Washington Square. There are two ironies in this building. The first is that for almost a century the largest interior well in an American library had been that of the Peabody Library in Baltimore (1878), which because of its size had signaled the end of the earlier book-hall style of library architecture. The second irony is that on the outside the NYU Library looks like an unmitigated box.

By this time, however, some of the more deleterious effects of atria in libraries were becoming apparent, and efforts were made to render them less obtrusive. In the first place, they were all scaled back in 
size. The University of Utah (1967) and Lehigh University (1984) glassed in their atria from the start to reduce sound transmission, and, after more than a decade, Stanford University was able to obtain funds to encase in glass the atrium in its undergraduate library so as to diminish the decibel level in the building's center. Some newer libraries, such as the Western Illinois University Library (1978), reduced the acoustics problems of their atria by lining them at all levels with utilities or other functions less likely to be disturbed by sound. Others with existing wells sometimes attempted to mask the obtrusive sounds transmitted through them by installing a bubbling fountain at the lowest level. Called "sound perfume" by some, this step was considered at Delta State College (1968) and Illinois Wesleyan University (1968), and it was tried at Butler University (1963) with little success.

Despite uniformly poor experience with wells and high ceilings in academic libraries, they continue to be built in evergrowing numbers. The University of Chicago (1970), Clark University (1968), Hamilton College (1972), and St. Mary's College at Notre Dame (1982) are only a handful of the many libraries built in the United States in the last twenty years that have been plagued to a greater or lesser degree by one or more of the four problems of atria or wells enumerated above.

\section{Monumentality}

For more than four millennia prior to the Renaissance, libraries served primarily temple and palace functions, and they were therefore almost always housed in monumental structures appropriate to their status. Even the alcoved book-hall libraries, used almost universally in the United States until 1880, were adapted directly from cathedral architecture, complete with narthex, nave, aisles, and apse, bringing library monumentality close to the present era. Considering this very recent palatial heritage of library architecture, it is not surprising that the fixedfunction libraries built between 1910 and 1940 continued to use monumental elements.

Monumentality in library buildings can take many forms. In general, the term refers to almost any building element that exceeds in size or cost what is necessitated by its function. Thus much of what was discussed earlier in this paper on irregular building shapes and open wells also can be classed as monumentality. Over-broad entries, elevated podiums, sumptuous building materials, grandiose staircases, as well as conspicuously crafted accessories, can, and in library buildings usually do, constitute monumentality.

High ceilings are often said to be monumental, and in many cases they are, but in the early decades of this century they were also often essential to good functional library design. The handy $71 / 2$-foot floor-tofloor dimension of the multitier structural steel stacks used during that period almost dictated that multiples of that dimension be used elsewhere in the building (if floors were to meet), encouraging high ceilings, especially in reading rooms. Large windows, moreover, could supplement the limited illumination available from incandescent lamps and, in the absence of air conditioning, could be used to exhaust the heat build-up.

The modular style of the last three decades, however, when used in conjunction with modern lighting and air treatment, eliminated all functional need for ceiling heights above $81 / 2$ feet, thus uncoupling library design from its princely origins and allowing the development of utilitarian library structures appropriate to their present-day egalitarian societal role. Yet, as with atria, some vestigial monumentality in ceiling heights continues to survive. Examples may be seen at St. John's University (1966) and at Colgate University (1982), where high ceilings were used for esthetic rather than for functional reasons. High ceilings, as with atria, necessitate larger areas of exterior skin to enclose the building, and they create sonic, illumination, and air-treatment problems that today's library users should not have to endure.

Other kinds of monumentality, however, have declined in use since the advent of the module. To be sure, a softer material with better acoustical properties would have been more practical in the vast 
NYU library lobby than its pretentious, expensive, and resounding marble. Curvacious stairs can often be very fetching and achieve a monumental effect, but they also are conducive to vertigo and are likely eventually to be eliminated by building codes. Nonetheless they continue to be widely used in libraries, as at Adelphi College (1963), Scarritt College (1968), Fisk University (1969), and Rosary College (1970).

In other efforts to achieve monumentality, some library buildings designed in the last two decades gave up the flexibility of the module, so much appreciated by librarians, and returned to the fixedfunction constraints of the earlier style. The libraries at Clark University (1968) and at St. Mary's College at Notre Dame (1982), for example, both incorporated very low ceilings where stacks were initially installed, and very high ceilings or wells and fixed task lighting in some other locations, rendering any future effort to revise layout difficult, if at all possible, to accomplish. The greatest impairment of future flexibility has been the relinquishing in many buildings of the principle of modular ceiling lighting. A desire to "play," "bathe," and "landscape" with light, rather than to use it for library purposes, led to the construction of some buildings, as at Wells College (1968) and the School of Business at Indiana University (1981), that are virtually unalterable because it would be too costly to change the lighting. Other libraries, meanwhile, lost flexibility because they lacked adequate floor-loading capability to permit stack relocation into certain areas, as into the cantilevered extensions of the upper levels of the Sangamon State University building (1976).

\section{Too Much or Too Little Glass}

Only one of the problems reported by Metcalf twenty years ago has been eased; that is the use of too much or of too little glass. Direct sunlight has never been good for reading purposes, and indirect natural light is available for reading during only one half the hours that a library is open.

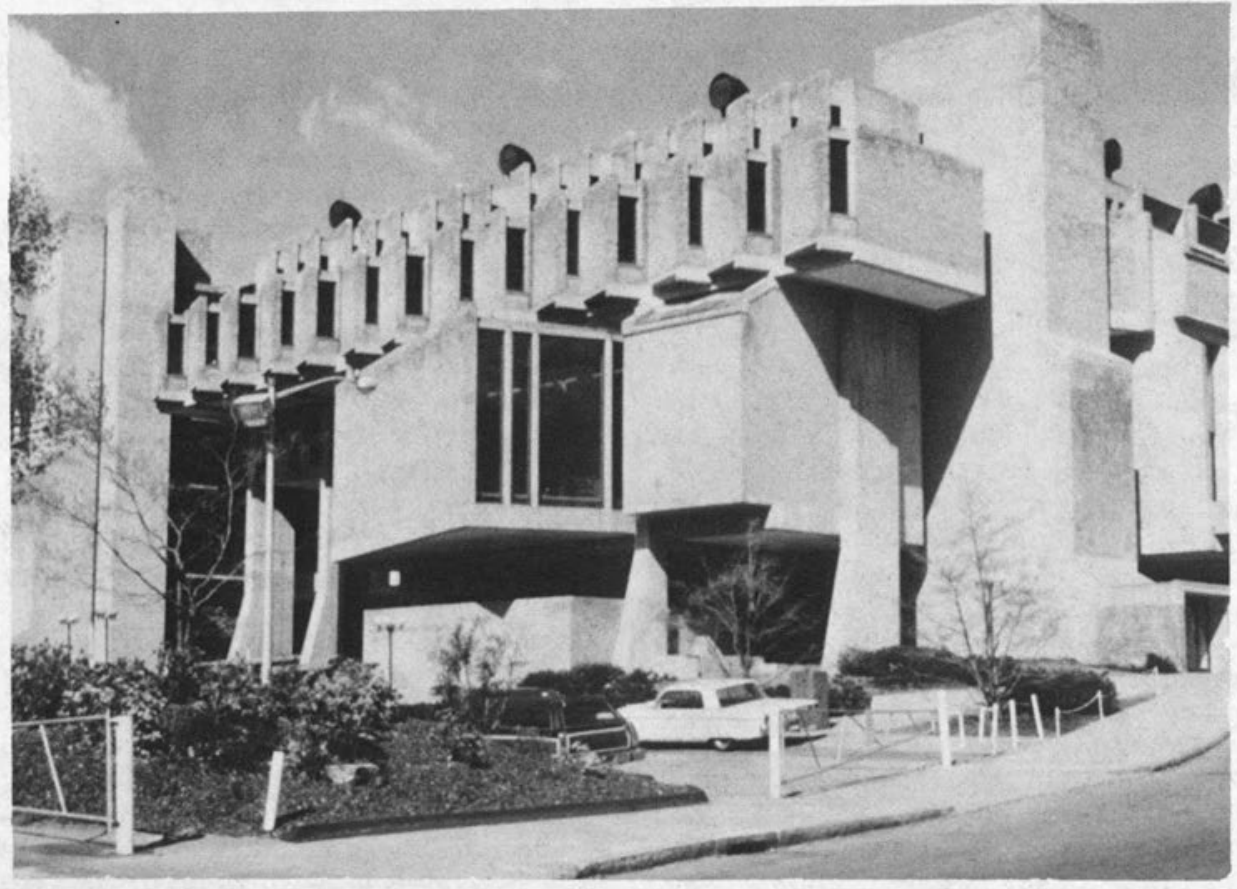

Clark University: a fixed-function "box." 
Although the full measure of the deleterious effects of sunlight on book-paper has only recently become clear, it has long been known to bleach bookbindings. For these reasons, librarians have long eschewed windows on any but the north facades of their buildings.

Prior to the availability of modern florescent lighting, libraries had to rely heavily upon natural light, and the extensive fenestration used in many of the older fixedfunction buildings was carried over into the early modular libraries. Furthermore, as a recently developed building material, glass enjoyed unusually wide popularity that, although perhaps warranted in some kinds of structures, caused severe problems for libraries. Among libraries from this period suffering from the overuse of glass were those at Grinnell College (1959), Butler University (1963), Clafin College (1967), and the University of California at San Diego (1970).

Overuse of glass in the 1950s and early 1960 s brought on a modest revulsion against it, resulting in some buildings being built with few if any windows. To be faddish, it seemed that buildings built around 1965 had to be faced either entirely of glass or completely without it. Among "under-windowed" library buildings constructed during this period were those at Oral Roberts University (1966), Rochester Institute of Technology (1967), and Indiana University (1968). This ambiguous situation prevailed at the time Metcalf commented upon the misuse of glass in libraries.

For the most part, relatively good sense has been used in the employment of glass in library buildings since that time. The introduction of mirror glass for building exteriors in the mid-1970s led for a time to its overuse. The Benedict College Library (1976), for example, was built of mirror glass, and the addition to the Vassar College Library (1976) was originally planned in mirror glass, although it was changed prior to construction because of its energy inefficiency. In most recent library buildings, however, concern for function has resulted both in limited fenestration, based upon the needs of library users rather than upon some counterproductive esthetic effect, and in the proper use of exterior sunscreens rather than reliance upon drapes or indoor blinds requiring frequent replacement. Nevertheless, because of the large number of poorly fenestrated library buildings already in use, librarians justifiably study with a jaundiced eye all proposals for windows in new space.

\section{NEW DIRECTIONS}

Among the many restricting realities that academic library building planners had to face during the period under discussion were increasingly high real estate costs, limited construction space, and reluctance to obtrude a building unnecessarily upon remaining vistas. As a result, a number of high-rise and below-grade library buildings were constructed. If these had been the only reasons for their use, high-rise and below-grade buildings might have rested comfortably in their accomplishment, but unfortunately other, nonfunctional, considerations sometimes also came into play, limiting their success.

Up...

High-rise library buildings were not an invention of the last quarter century. The New York Mercantile Library and the first John Crerar Library buildings were highrise buildings, both built well over sixty years ago, but they were not academic libraries. On the other hand, the twentyeight-story Cret building at the University of Texas (1934), the library tower at Fisk University (1936), and the nineteen-story Hoover Institution at Stanford University (1940) were academic libraries, so university librarians in 1960 were not wholly lacking in experience with them. Thus when the University of Notre Dame built its present fourteen-story library building (1963), many old heads questioned its wisdom. Rather than being dictated by library functional factors, this building's height was determined by the university's desire for a symbol of its academic excellence that would outshine its reputation for football prowess. The library fulfilled that symbolic purpose admirably, with its mosaicbedecked facade visible from 60 percent of the seats in the stadium. Happily, also, 
Notre Dame: irreverent undergraduates believe Christ signals "Touchdown!"

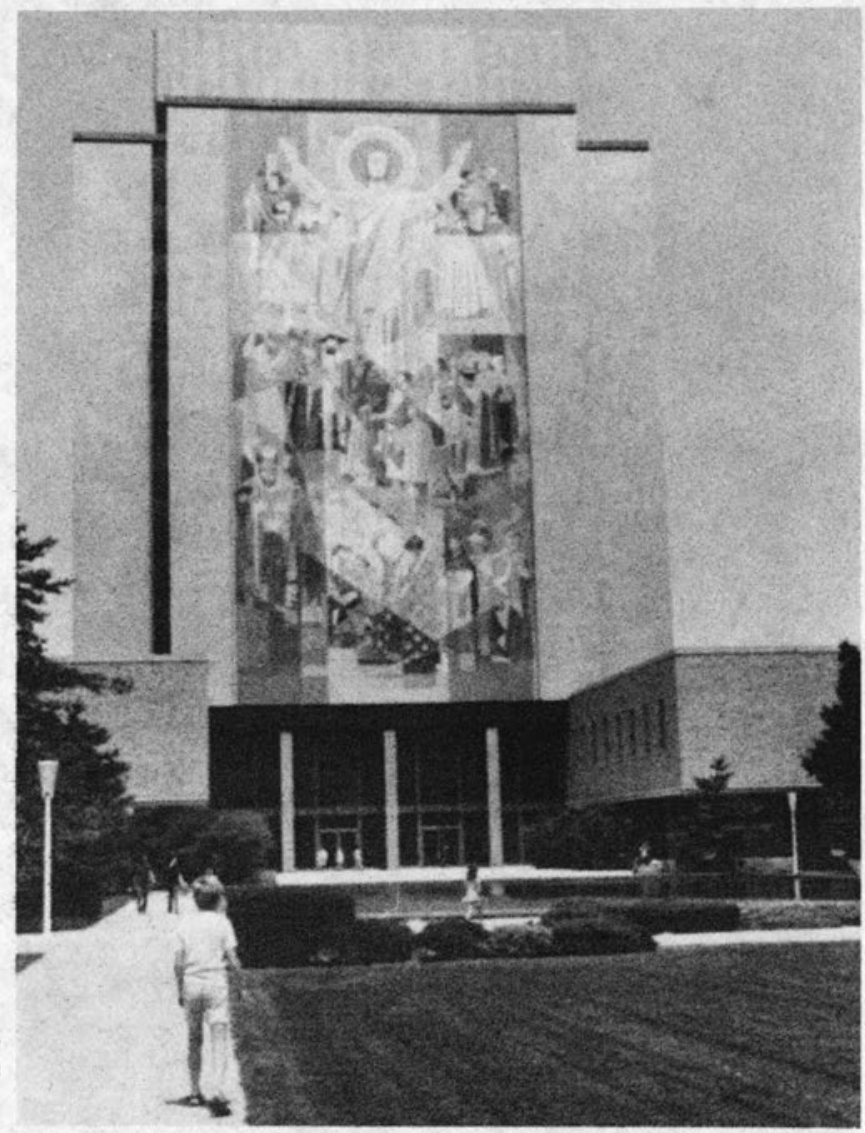

the building worked quite well as a library, since the assignable area on each tower floor was large enough to permit the effective deployment of an ample admixture of stack and reader facilities, a condition not true of the earlier buildings at Texas, Fisk, and Stanford.

This first high-rise library in a quarter century inspired others to try similar schemes, but perhaps none has been so successful, and some have been abysmal failures. Were it not for its unique program requirement to bring departmental libraries under a single roof and yet enable them to retain some semblance of their individual integrity (a dubious political decision rather than a sound library decision), the fourteen-story science library at Brown University (1966) would certainly have been disproportionately tall. The ten-story height of the library at Hofstra University (1967) may have exceeded an optimal ratio to its breadth and depth, and the stack tower at Memphis State University (1968) clearly did so. The misbegotten twenty-eight-level library structure at the University of Massachusetts (1972) has the single virtue that no one has yet exceeded it in height. If history can serve as a guide, however, and if institutions continue to demand that their library buildings serve a symbolic function, then it seems likely that the height even of this towering ziggurat will eventually be surpassed, doubtless with equally dismal results.

\section{... and Down}

Burying library buildings, or at least large portions of them, below grade was an innovation of the period being dis- 


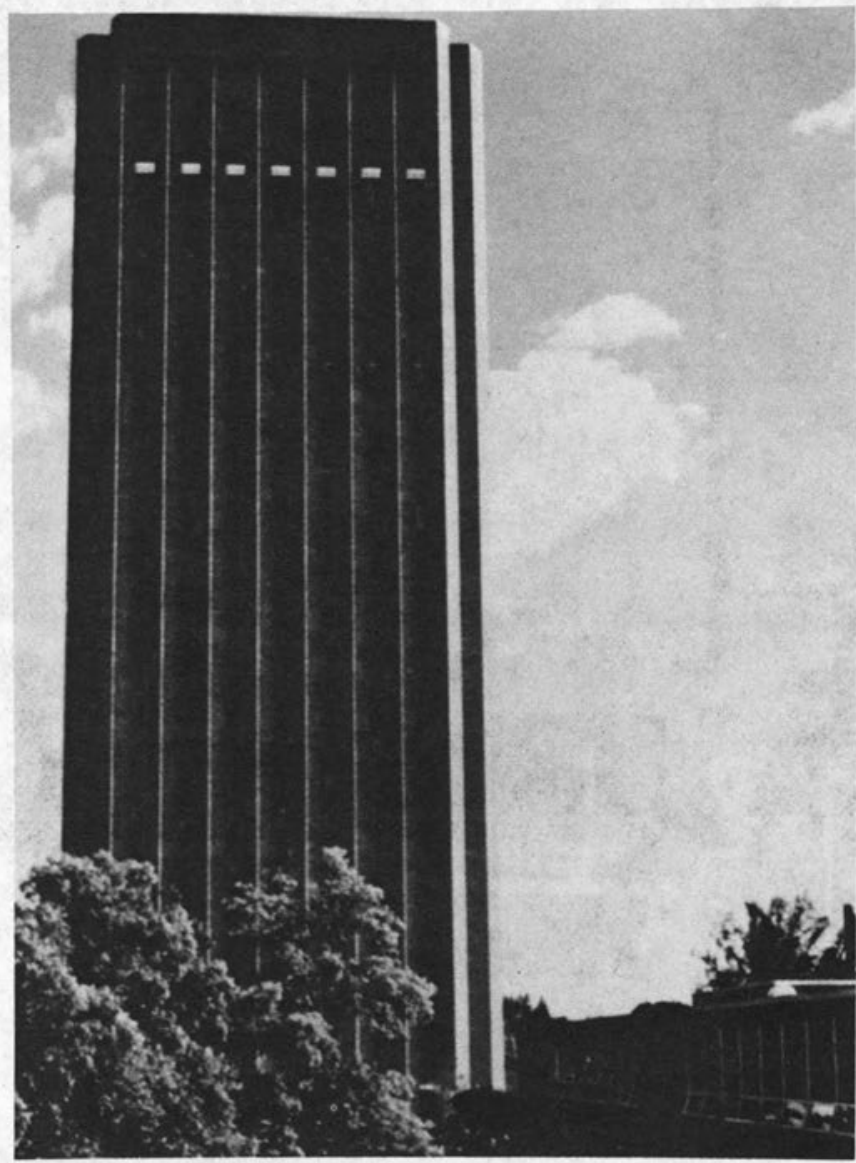

University of Massachusetts: a "towering ziggurat" of twentyeight floors. cussed here, and this was generally much more successful than the aforementioned efforts to go up. In the 1960s the principal reasons for constructing libraries below grade were (1) to keep their large bulk from overwhelming adjacent structures or areas, or (2) to keep an important site or view unobstructed. The first reason accounted for the location below grade of fully half of the floor area of the Washington University Library in 1962 and more than three fourths of the Johns Hopkins University Library in 1964.

Meanwhile, the second consideration accounted for the first library building to be constructed completely below grade at Hendrix College in 1967. Here the only satisfactory site was at the center of the one campus quadrangle where a conven- tional building would have blocked all views and circulation, so a two-level building was sunk into the ground and the occasion used to relandscape the quad above. In 1968 two other libraries, the science library at Vanderbilt University and the undergraduate library at the University of Illinois, were built completely below ground for somewhat similar reasons. The former was sited below ground to enable it to serve an engirdling ring of laboratory and classroom buildings without visually encroaching upon their quadrangle, and the latter to attain proximity to the main library without casting a profaning shadow upon the sanctity of the Morrow experimental corn plots, a compelling concern in the state of Illinois.

In the early 1970 s a third reason for 


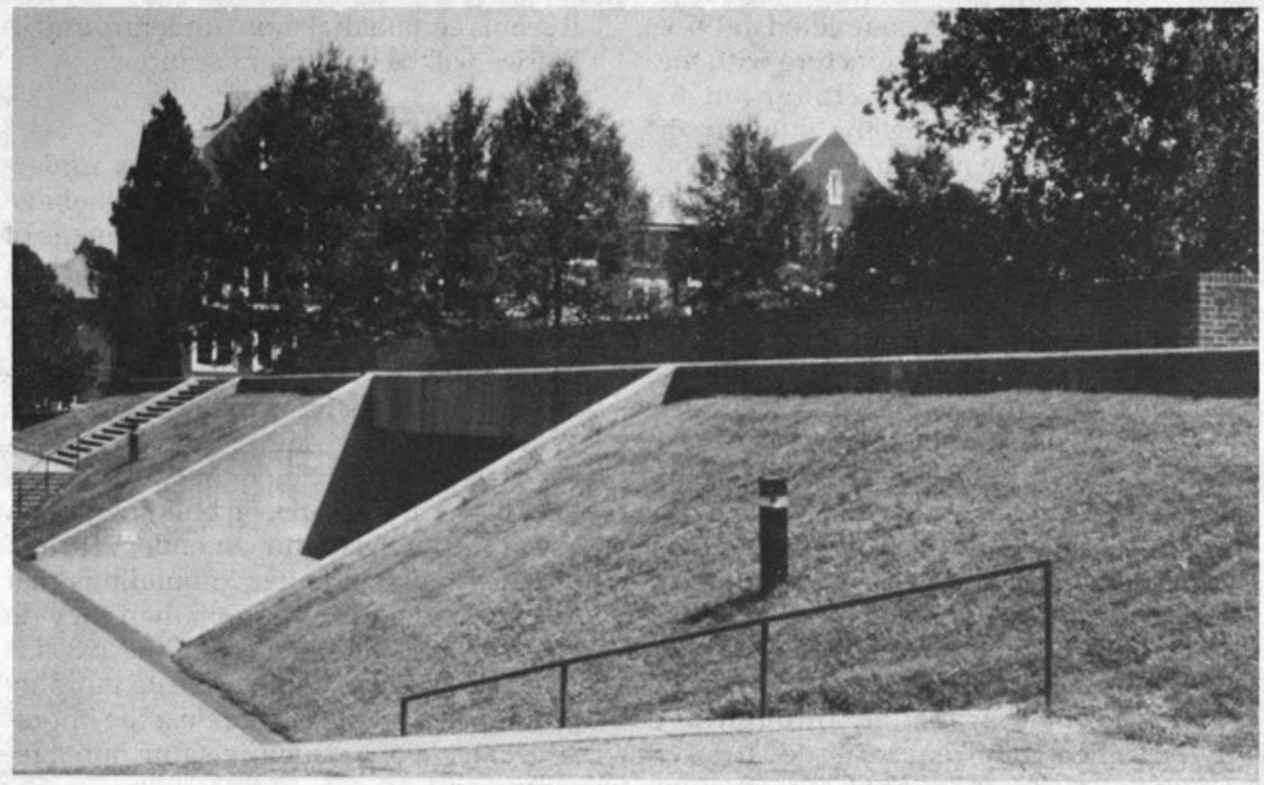

Hendrix College: the first library completely below grade.

building below ground became prominent. It was the energy efficiency of such a structure, and a number of underground or partially underground libraries were built in order to gain this economy. Some were set into hillsides, cropping out to the leeward, such as the libraries of Scripps Institute of Oceanography (1976) and St. Meinrad College (1983). Others continued to be built for reasons other than energy efficiency, although they enjoyed that benefit as well. Among them was the Pu-

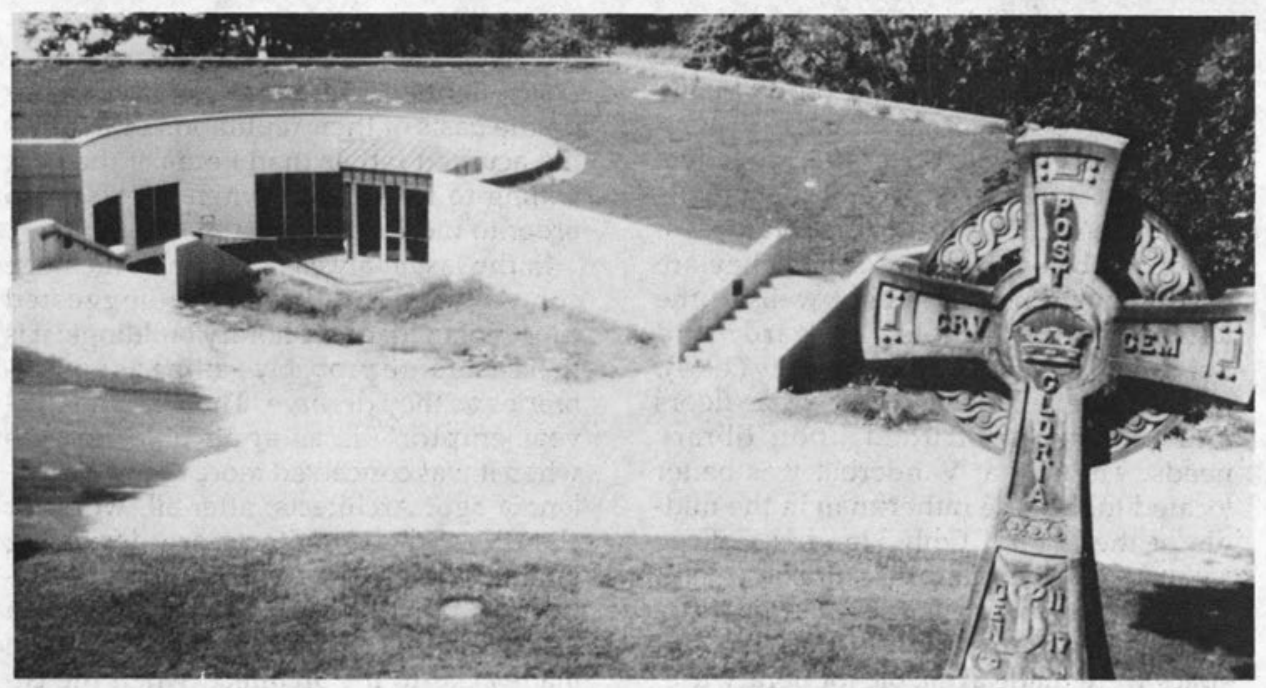

St. Meinrad College: underground floors crop out to the leeward. 
sey Library at Harvard, completed in 1976. Here the need to effect a juncture with the Lamont, Widener, and Houghton libraries while preserving the integrity of the Yard led to the planning of a five-level below-grade structure, although for cost reasons its height was reduced to three levels before it was built. Likewise for site reasons, the University of Michigan Law Library was expanded below grade in 1981 , with much more success than a previous expansion in 1955, when a ghastly addition in glass and aluminum was performed upon the graceful Gothic splendor of the Cook law quadrangle.

Considering the level of popular apprehension regarding underground libraries, surprisingly few problems have been encountered with them. No more water comes into them than comes through skylights or, for that matter, through flat roofs. Since they require little, if any, costly exterior facade, they can often be constructed as cheaply as, or cheaper than, conventional above-grade structures, and modern lighting and air treatment can render them as habitable and gracious as any other interior space. Since they have no exterior visible form, there is no temptation to contort them into irregular shapes or masses inimical to sound library function.

One problem common to almost all below-grade libraries built thus far, however, has been their reliance on exterior wells to bring natural light (and usually vegetation) down into their interiors. $\mathrm{Ob}$ viously done to mask over the troglodyte character of these spaces, such wells nonetheless create the same library dysfunctions below grade as when they are used above grade. The light wells at the University of Illinois, Harvard, and Beinecke Library at Yale University (1964), for example, all pierced the service floors and therefore obtruded upon library needs. The one at Vanderbilt was better located to the side rather than in the middle of the library. Only Hendrix College resisted the temptation to utilize a light well, and two full levels of uniformly good, rectangular, totally flexible loft space were made available for library use.
It seems certain that more underground libraries will be built in the future.

\section{CONCLUSIONS}

Given these experiences, it is understandable why many librarians believe that they are getting a lower percentage of satisfactory new buildings today than they were twenty years ago. A more important issue, perhaps, if the perception be accurate, is why the percentage of satisfactory buildings has declined. The cases enumerated above suggest several possible causes. They include the following:

1. Fashion is as fickle in building design as in other areas of human endeavor, and libraries function better in buildings that fit the simpler tastes of 1960 than they do in the more complex styles of the $1980 \mathrm{~s}$.

2. Librarians sometimes write building programs that fail to make clear the imperative nature of a structure's functional requirements.

3. Institutional officers, trustees, and donors sometimes append extra-library codicils to the program, often orally, that are inimical to library function.

4. Architects sometimes flout program requirements or gloss over their infidelity to them, until it is too late for the building to be rescued.

5. Clients sometimes fail adequately to monitor the work of architects or to insist upon adherence to the program as written.

6. Clients sometimes select architects on the basis of their reputation or marketing acumen rather than because they are willing to forgo effect when necessary in order to meet function.

In the last analysis, a common message comes through all of these suggested causes of inadequate library buildings: it is that clients are probably getting as good libraries as they deserve. The warning "caveat emptor" is as applicable here as when it was conceived more than two millennia ago. Architects, after all, work for clients, and if architects are designing poor buildings, it is because clients are accepting poor buildings. When a client wants a piece of sculpture, that should be made clear to the architect; when the cli- 
ent wants a library, that should be made clear to the architect, but if both are to inhabit the same structure it should be made clear to the architect which should domi- nate the other. It is in everyone's interest that better academic library buildings be built in the years ahead than have been built in the last quarter century.

\section{REFERENCES}

1. Charles Baumann, Angus Snead Macdonald (Metuchen, N.J.: Scarecrow, 1972), p.118-37.

2. Ralph Ellsworth, Ellsworth on Ellsworth (Metuchen, N.J.: Scarecrow, 1980), p.40-50.

3. Ralph Ellsworth, Planning the College and University Library Building (Boulder, Colo.: Pruett Pr., 1968), p.123.

4. Keyes D. Metcalf, Planning Academic and Research Library Buildings (New York: McGraw-Hill, 1965), p.21-23.

5. Ralph Ellsworth, Academic Library Buildings (Boulder: Colorado Associated University Pr., 1973), p.42. 